\title{
M otivação e condicionantes para a gestão ambiental nas maiores indústrias exportadoras do estado do Ceará
}

\author{
Danielle Batista Coimbra * \\ Francisco Correa de Oliveira**
}

\begin{abstract}
Resumo
Na sociedade atual as questões ambientais assumem importância crescente começando a influir cada vez mais nas decisões estratégicas das empresas. Este é um desafio que exige boa gestão e apresenta-se como um desafio permanente ante as exigências de uma legislação estatal mais rígida e uma mudança de valores na sociedade, que promovem uma rejeição a modelos organizacionais que colocam o meio ambiente em segundo plano. 0 Estado do Ceará vêm apresentando um crescimento significativo no seu parque industrial, o que leva a uma preocupação em relação aos impactos gerados por estas indústrias. Assim, o objetivo geral da pesquisa é investigar o comportamento das maiores indústrias exportadoras do Ceará, considerando seus condicionantes e motivações para o investimento em ações de gestão ambiental. A metodologia utiliza métodos quantitativos na análise de dados com o auxilio do software Sphinx e tem uma abordagem qualitativa na interpretação das entrevistas. A coleta de dados primários foi realizada junto aos principais responsáveis pela política ambiental das maiores empresas exportadoras do Estado, por meio de survey na modalidade de questionários estruturados. 0 universo foi determinado em função da maior exposição à mercados externos. 0 critério para seleção das empresas foi o faturamento anual em exportações, que deveria ser superior a U\$ 1 milhão. Foi realizado um censo já que o numero total de empresas que atendia ao critério estabelecido, limitou o universo a 55 unidades. A pesquisa apresenta em seus resultados de forma clara, a força da relação entre as pressões externas e respostas das empresas, ou seja, a identificação de uma postura empresarial ambiental predominantemente reativa no que se refere aos investimentos em gestão ambiental, porém, estas pressões têm sido necessárias para que as empresas mudem sua concepção acerca do tema meio ambiente.
\end{abstract}

Palavras-chave: Gestão ambiental, condicionantes, motivação

\begin{abstract}
Environmental management is posing a great challenge to firms and also a permanent test to CEO"s in face of the demands derived from a more rigid state legislation and a higher pressure from changing social values. The industrial park of the State of Ceará is presenting a significant growth, leading to a greater concern over environmental impacts generated by these industries. So, the general objective of this research is to study the largest industrial exporters' of Ceará, considering their conditionings and motivations for investment in actions of environmental management. The methodology uses quantitative methods that were analyzed with the usage of Sphinx software. Data were collected with interviews to the CEO"s of the largest exporters, and high ranked government officials. Only companies with annual revenue above US $\$ 1$ million were selected. A census was made since the number of companies in those conditions was limited to 55 units. A research pointed to a close relation between the external pressures and environmental answers from the companies. These pressures were necessary so that firms could improve their environmental actions.
\end{abstract}

Key words : Environmental management, condition, motivation

\footnotetext{
* Professor Auxiliar da Universidade de Fortaleza - Unifor. Mestre em Administração. E-mail: daniellecoimbra@ unifor.br. Endereço: Universidade de Fortaleza UNIFOR. Secretaria Centro de Ciências Administrativas - CCA. Av Washington Soares, 1321. Bairro: Edson Queiroz. CEP: 60.811-905 - Fortaleza - Ceará.

** Professor Titular da Universidade de Fortaleza - Unifor. Professor da Universidade Estadual do Ceará. E-mail: oliveira@ unifor.br. Endereço: Universidade de Fortaleza - UNIFOR. Secretaria Centro de Ciências Administrativas - CCA. Av Washington Soares, 1321. Bairro: Edson Queiroz. CEP: 60.811-905 - Fortaleza - Ceará. 


\section{Introdução}

Nos últimos 30 anos, especialmente desde a Conferência de Estocolmo, a questão ambiental se tornou prioritária e definitiva na agenda internacional. Nesse contexto, os problemas relacionados ao meio ambiente estão cada vez mais presentes nas decisões empresariais e a sociedade está mais exigente, o que tem levado o mercado a demandar ações mais efetivas quanto à qualidade de vida. A cada dia são desenvolvidos novos instrumentos que visam promover um maior respeito ao homem e ao meio ambiente. Isso acaba exigindo mais das empresas, do ponto de vista da gestão, num desafio permanente para atender uma legislação mais rígida e corresponder a uma mudança de valores na sociedade que tende a rejeitar modelos organizacionais que subestimem a questão ambiental

No Brasil, nos últimos anos, o estado do Ceará vem experimentando um crescimento significativo no seu parque industrial, principalmente, em conseqüência dos incentivos concedidos pelo governo estadual, que vê no estímulo à industrialização um mecanismo de fomento ao crescimento econômico. Por isso existe a preocupação com o impacto ambiental causado pela instalação indiscriminada de indústrias. Se por um lado a industrialização gera emprego e renda com crescimento econômico, por outro lado é importante verificar se ela também traz desenvolvimento. Por definição, o crescimento econômico desconsidera uma série de fatores que não representam desenvolvimento. Na maioria das vezes, é muito alto o custo ambiental dos incentivos indiscriminados à industrialização.

Assim, o objetivo deste estudo é investigar o comportamento das maiores indústrias exportadoras do Ceará, considerando seus condicionantes e as motivações para o investimento em ações de gestão ambiental. A análise dos dados levantados foi feita pela metodologia quantitativa, com o auxílio do software Sphinx, e as entrevistas realizadas foram interpretadas segunda uma abordagem qualitativa. A coleta dos dados primários foi feita junto aos principais responsáveis pela política ambiental das maiores empresas exportadoras daquele estado, através de levantamento por questionários estruturados. O universo foi determinado em função da maior exposição a mercados externos. O critério para seleção das empresas pesquisadas foi o faturamento anual com exportações superior a US\$1 milhão; e feito um censo, apenas 55 empresas se enquadraram nesse parâmetro. A pesquisa revela claramente a forte relação entre as pressões externas e as respostas das empresas; ou seja, constatou que a postura das empresas é predominantemente reativa no que se refere aos investimentos em gestão ambiental. Essas pressões, contudo, são necessárias para que as empresas mudem sua concepção sobre o meio ambiente.

\section{A evolução das questões ambientais e seus condicionantes}

Os problemas ambientais se agravam a cada dia. Não surgiram de um dia para o outro; ao contrário, são conseqüência de um acúmulo de ações irresponsáveis ao longos dos anos. No Brasil, é uma preocupação desde a época colonial, quando se procurava evitar que o modelo de exploração predatória adotado por Portugal comprometesse os recursos naturais. Fica claro, portanto, que a idéia de gestão ambiental resulta de conceitos formados ao longo de muito tempo.

No entanto, a partir da década de 1970, os problemas relacionados ao meio ambiente assumiram um significado diferente do verificado até então, ganhando um peso cada vez maior nas decisões empresariais. A legislação se torna mais rígida e em escala mundial ocorre uma mudança de valores. Dessa forma, um dos maiores desafios neste novo milênio é fazer com que as forças de mercado respeitem o meio ambiente, a partir de padrões de desempenho e de uso criterioso de instrumentos econômicos, num quadro de regulamentação.

Nesse contexto, há uma forte tendência de se considerar o problema ambiental como uma das grandes questões estratégicas da sociedade contemporânea, o que não ocorria há algumas décadas. A gestão ambiental ocupa lugar de destaque, e passa por um necessário e obrigatório processo de internalização nas empresas (TACHIZAWA, 2002). Esse processo nada mais é do que uma resposta natural ao novo mercado e às suas imposições. Ele torna evidente a necessidade de que as organizações partilhem de um objetivo comum, pautado 
pelo entendimento de que não deve haver conflito entre crescimento econômico e preservação ambiental. A legislação vigente, a internacionalização dos padrões de qualidade ambiental e a conscientização dos consumidores, dentre outros fatores, levam as empresas a dispensarem maior atenção à questão ambiental e a se preocuparem com a qualidade de vida da população. Assim, os empresários vêm aderindo à gestão ambiental, entendida como um conjunto de procedimentos claramente definidos para redução e controle do impacto ambiental (VALLE, 1995).

Apesar do reducionismo ao se lidar com o problema, particularmente no meio empresarial, já há uma mudança de atitude. Podemos observar uma gradativa evolução nas ações, ainda que não sejam motivadas apenas por uma questão de consciência. O surgimento e o desenvolvimento de mecanismos para internalizar os custos ambientais revelam em grande parte essa evolução. As mudanças na sociedade têm levado as empresas a adotarem medidas de promoção do desenvolvimento sustentável (CSILLAG \& CSILLAG, 2001). Na verdade, não se trata propriamente de conscientização, já que o termo deriva de consciência, ou seja, algo espontâneo que surge independentemente de pressão, apenas pela necessidade de contribuição.

Com relação ao meio ambiente e às ações para protegê-lo, na maioria dos casos, são os fatores externos que ainda determinam as estratégias adotadas pelas empresas. Percebe-se, então, que o movimento espontâneo pela preservação do meio ambiente ainda não é significativo ou não caminha por si só. Acima dessa consciência estão a lei e o mercado, e sem essas exigências, as organizações não estariam investindo em sistemas de gerenciamento ambiental. (NOELI, 2001).

\section{Agentes de pressão}

As pressões sobre o mercado são exercidas por atores que, ao atuarem nas atividades econômicas, acabam levando a preocupação ambiental para os seus negócios. Em geral, essa preocupação de manifesta de modo diferenciado, conforme os diversos setores da economia e seus respectivos segmentos. Em cada caso, um nível de impacto e um tipo de risco. Em alguns setores, pela maior visibilidade de suas práticas, é maior a pressão para que considerem a questão ambiental. Os agentes indutores pertencem a dois grandes grupos: a sociedade civil organizada e o governo, que merece destaque, pela sua força. O governo precisa intervir, já que a mão invisível do mercado não consegue alinhar os interesses do indivíduo ou da empresa individual com os interesses da sociedade (CAIRNCROSS, 1992).

As mudanças na orientação governamental foram o primeiro passo concreto para mudar o comportamento empresarial em relação ao meio ambiente. As regulamentações e discriminações que dificultavam a possibilidade de atuação e localização das indústrias provocaram modificações na orientação das organizações produtivas. A necessidade de rever diretrizes e planos referentes ao meio ambiente torna-se condição primordial para a realização de bons negócios e para a própria sobrevivência da empresa no mercado. $\mathrm{O}$ governo tem a obrigação de assegurar julgamento equânime ao adotar medidas que afetam toda a sociedade no que se refere à dimensão ambiental. É sua incumbência, desenvolver mecanismos de proteção ao meio ambiente, seja criando incentivos para a adoção de práticas ambientais corretas ou adotando regulamentações e mecanismos de mercado que inviabilizem a atuação das empresas ambientalmente incorretas. (NIZARD \& TOURNON, 1974).

Por sua vez, a sociedade civil organizada também pressiona as empresas por mudanças; e nela, segundo Miranda, Samudio e Dourado (1997), a pressão mais forte vem dos consumidores verdes, dos grupos ambientalistas, das empresas de seguro e dos investidores verdes.

\section{Mudanças no contexto ambiental}

O crescente comprometimento com as questões ambientais é resultado da ação dos agentes anteriormente citados. No meio empresarial, iniciativas ambientalmente corretas de caráter espontâneo ainda são utopia. As consequiências dessa mentalidade são nefastas até para a sobrevivência da espécie humana num planeta que se ressente dos maus tratos e que "responde" com mudanças globais ameaçadoras. 
O foco do problema são as atividades industriais, responsáveis diretamente por grande parte da degradação ambiental, seja pela extração dos recursos naturais ou pelo uso ou descarte de produtos finais. (BARBIERI, 2004). Além disso, a mentalidade consumista também é produto indireto da atividade industrial, estimulando o uso intensivo dos recursos naturais. Sem dúvida, outra configuração do contexto industrial depende do empenho dos empresários em tomar decisões corretas que não danifiquem o meio ambiente.

A tese de que os danos ambientais são o preço inevitável a ser pago pelo desenvolvimento vai perdendo sustentação, e empresas poluidoras têm sua imagem arranhada perante a opinião pública.(LAYARGUES, 1998). Mesmo assim, as mudanças acontecem predominantemente em função dos agentes de pressão. Portanto, se a pressão desses agentes ainda é a única maneira de se conseguir a proteção do meio ambiente, que então seja difundida e se torne cada vez mais exigente, condicionando os empresários a priorizarem a questão ambiental em suas atividades. Ainda que não seja o ideal, pois as ações ficam limitadas ao exigido, a liberdade absoluta é muito pior, já que os problemas estão se agravando. Muitos empresários acham que estão fazendo muito, quando na realidade estão fazendo menos que o suficiente. Esse quadro deve ser revertido. Muitas das soluções já existem, mas devem ser postas em prática. Chegou o momento em que as questões de ordem política e econômica devem ser suplantadas pelas de interesse social. (ALMEIDA, 1999).

\section{Metodologia}

Este artigo mostra um estudo descritivo da indústria no estado do Ceará, que apesar da metodologia qualitativa, também se valeu de métodos quantitativos para a análise de dados. As variáveis básicas consideradas foram relacionadas, sobretudo, à importância da gestão ambiental para os empresários, à consciência destes sobre o impacto ambiental causado por suas atividades e também aos fatores que motivam ou condicionam os investimentos na área ambiental.

Este estudo buscou caracterizar os dados sobre as práticas ambientais naquele estado, especificamente no setor industrial, dando uma visão da importância atualmente dispensada pelo segmento industrial ao meio ambiente. O objetivo era investigar o comportamento das maiores indústrias exportadoras do Ceará em relação às questões ambientais, considerando seus condicionantes e motivações para investirem em ações de gestão ambiental. Mais especificamente, foram analisados aspectos como:

- nível de conscientização dos empresários, através da importância dispensada ao tema;

- os fatores condicionantes para a realização de ações de gestão ambiental e

- a visão dos empresários quanto à realização de investimentos nessa área.

Para o levantamento bibliográfico e documental, foram visitados órgãos como a Secretaria Estadual do Meio Ambiente, a Superintendência Estadual do Meio Ambiente (Semace) e o Instituto Brasileiro de Ações do Meio Ambiente (Ibama). A pesquisa de campo fez um estudo descritivo da indústria cearense, através de questionário estruturado que levantou as variáveis básicas da pesquisa.

O universo investigado abrange todas as empresas exportadoras do Ceará, consideradas a partir da relação de empresas exportadoras por unidade da Federação de 2002, disponível no portal do Ministério do Desenvolvimento, Indústria e Comércio (MDIC), na seção Indicadores e Estatísticas - Estatísticas de Comércio Exterior. O documento relaciona as empresas exportadoras daquele estado por ordem alfabética - além de fornecer outras referências, como CNPJ e endereço - destacando a faixa de faturamento total do período, em US\$ FOB, relativa às exportações de cada companhia. O documento registra um total de 262 empresas classificadas em faixas de valores que compreendem quatro padrões de faturamento, os quais foram verificados e organizados por faixa de valor, para que fossem identificadas as maiores empresas em cada faixa, obtendo-se os quantitativos correspondentes. 
Quadro 1 - Maiores empresas exportadoras do Ceará por faixa de aturamento Ano base 2002

\begin{tabular}{cc}
\hline FAIXA DE FATURAMENTO (US\$ FOB) & NÚMERO DE EMPRESAS \\
\hline Até 1 milhão & 193 \\
\hline De 1 a 10 milhões & 56 \\
\hline De 10 a 50 milhões & 12 \\
\hline A partir de 50 milhões & 1 \\
\hline TOTAL & 262 \\
\hline
\end{tabular}

Fonte: Ministério do Desenvolvimento, Indústria e Comércio MDIC - Secex 2002.

O documento possibilitou identificar as empresas pela respectiva faixa de valor exportado, considerando-se, inicialmente, como maiores, as 55 firmas com volume de exportação a partir de US\$1 milhão. Com base nesses dados, foram identificados os setores onde cada empresa atua, o que permitiu saber quais as maiores exportadoras e sua classificação nos principais setores da cadeia produtiva da indústria exportadora cearense. Os principais segmentos da indústria exportadora do estado foram identificados a partir da classificação por setor da Federação das Indústrias do Ceará (Fiec) e do Centro Internacional de Negócios (CIN). O quadro 2 mostra os setores que são objeto deste estudo, por ordem decrescente de faturamento com as exportações em 2002, e os relaciona às suas entidades representativas.

Quadro 2 - Setores da indústria selecionados para pesquisa e entidades representativas

\begin{tabular}{ll}
\hline SETOR & ENTDADE PATRONAL \\
\hline Coureiro/calçadista & $\begin{array}{l}\text { Sindicato das Indústrias de Curtimento de Couros e Peles no Estado do } \\
\text { Ceará / Sindicato da Indústria de Calçados de Fortal eza }\end{array}$ \\
\hline Têxtil & $\begin{array}{l}\text { Sindicato das Indústrias de Fiação e Tecelagem em Geral no Estado do } \\
\text { Ceará }\end{array}$ \\
\hline Castanha de caju & $\begin{array}{l}\text { Sindicato das Indústrias do Açúcar e de Doces e Conservas Alimentí- } \\
\text { cias do Estado do Ceará }\end{array}$ \\
\hline Lagosta & Sindicato das Indústrias de Frios e Pesca no Estado do Ceará \\
\hline Camarão & Não há representante formal do setor \\
\hline Gorduras, óleos e ceras animais e vege- & $\begin{array}{l}\text { Sindicato das Indústrias Refinadoras de Cera de Carnaúba do Estado } \\
\text { do Ceará }\end{array}$ \\
\hline Fruticultura & Sindfruta \\
\hline Confecções & $\begin{array}{l}\text { Sindicato das Indústrias de Confecção de Roupas e Chapéus de Senho- } \\
\text { ra do Estado do Ceará }\end{array}$ \\
\hline Outros freios e suas partes & $\begin{array}{l}\text { Sindicato das Indústrias M etalúrgicas, M ecânicas e de M ateriais Elétri- } \\
\text { cos no Estado do Ceará }\end{array}$ \\
\hline Outros & $\begin{array}{l}\text { Sindicato das Indústrias Químicas Farmacêuticas e da Destilação e Re- } \\
\text { finaria de Petróleo do Estado do Cearáa }\end{array}$ \\
\hline
\end{tabular}

Fonte: adaptado de CIN/Fiec (2002).

A opção por valores acima de US\$1 milhão excluiu automaticamente três dos setores citados no quadro 2, por não existirem empresas cujas exportações alcancem a quantia compreendida pela faixa selecionada. A opção por trabalhar com as maiores empresas exportadoras se justifica pelo fato de que, por estarem expostas às exigências do mercado externo, há (ou deveria haver) maior probabilidade de serem obrigadas a investir em gestão ambiental. Se tais empresas não estão comprometidas com investimentos relativos ao meio ambiente, presume-se que essa probabilidade é ainda mais restrita nas menores.

Portanto, foram pesquisados apenas oito dos 10 setores da indústria cearense:

- têxtil;

- do camarão, incluindo as modalidades de pesca e a carcinicultura (cultura dos crustáceos);

- da lagosta; 
- coureiro/calçadista;

- de beneficiamento da castanha de caju;

- de gorduras, óleos e ceras animais e vegetais;

- da fruticultura e

- de outros freios e suas partes, que incluem as atividades metalúrgica, elétrica e metal-mecânicas.

Todos os setores foram selecionados pelo critério de acesso. A coleta de dados primários foi feita através de pesquisa de campo nas empresas definidas na amostra, junto aos executivos. Os respondentes são seus representantes formais, na pessoa do presidente, diretor ou de colaboradores. Através de contatos pessoais ou, em alguns casos, por contato eletrônico, foi aplicado um questionário estruturado com base nas variáveis a serem consideradas. Parte das questões foi levantada pela coleta estruturada de dados, cujas respostas possíveis foram preestabelecidas numa forma escalar e objetiva. Como complemento, foram aplicadas outras questões não-formais, para aprofundar as respostas e enriquecer seu conteúdo. Além do questionário para levantar os dados objetivos, a pesquisa também contou com entrevistas programadas, para um detalhamento dos pontos considerados essenciais. O questionário foi elaborado com o auxílio do software Sphinx, que também serviu de base para a análise das respostas.

Quadro 3 - Variáveis-chave - (pesquisa direta)

\begin{tabular}{|c|c|}
\hline PERGUNTA & TIPO \\
\hline $\begin{array}{l}\text { Qual a empresa, nome ou a razão social, e o setor } \\
\text { industrial a que pertence? }\end{array}$ & \multirow{4}{*}{ Aberta } \\
\hline $\begin{array}{l}\text { Qual o cargo ocupado e o nível hierárquico do } \\
\text { respondente? }\end{array}$ & \\
\hline \multirow{2}{*}{$\begin{array}{l}\text { A quanto tempo a empresa está no mercado? } \\
\text { Para quais mercados a empresa exporta? }\end{array}$} & \\
\hline & \\
\hline Qual a importância do meio ambiente para a empresa? & \multirow{6}{*}{ Fechada única e múltipla } \\
\hline $\begin{array}{l}\text { Qual o nível de conscientização quanto ao impacto } \\
\text { ambiental, positivo e negativo, causado pela atividade da } \\
\text { empresa? }\end{array}$ & \\
\hline Qual o tratamento dispensado às questões ambientais? & \\
\hline $\begin{array}{l}\text { O que motiva e condiciona os investimentos em gestão } \\
\text { ambiental? }\end{array}$ & \\
\hline Sobre a implantação de um sistema de gestão ambiental. & \\
\hline $\begin{array}{l}\text { Quais as dificuldades para implantar um sistema de } \\
\text { gestão ambiental? }\end{array}$ & \\
\hline $\begin{array}{l}\text { Quais os trabalhos desenvolvidos pela empresa, } \\
\text { associados à idéia de responsabilidade social? }\end{array}$ & Aberta \\
\hline
\end{tabular}

Em aproximadamente $70 \%$ das empresas, o questionário foi aplicado diretamente aos gestores, o que possibilitou aprofundar tópicos considerados necessários quanto às suas escolhas, além da complementar as perguntas com informações importantes, principalmente, em relação ao entendimento do respondente sobre o tema abordado. $\mathrm{O}$ trabalho se dividiu em três blocos:

- um, relativo à percepção sobre as questões ambientais e o impacto causado pela atividade desenvolvida pelo respondente;

- outro, sobre as ações desenvolvidas pela empresa em relação às questões ambientais e os grupos de pressão que mais influenciam na decisões estratégicas da empresa; e

- sobre as especificidades de sistemas de gestão ambiental (SGA).

O questionário começou a ser aplicado na segunda semana de outubro de 2003 em cinco indústrias de setores distintos. Foi o teste para verificar previamente a adequação das questões e do instrumento. A adequação do 
instrumento também foi trabalhada do ponto de vista da sua construção através do software de apoio, pela revisão das suas partes. Feitos os ajustes devidos e verificada a aplicabilidade do instrumento, a abordagem prosseguiu.

Na avaliação dos resultados, inicialmente, foi analisada a parte quantitativa das informações objetivas, a partir do software Sphinx. Foram relacionadas as variáveis-chave da pesquisa, por setor e em seu conjunto, buscandose demonstrar o grau de conscientização do empresário em relação às questões ambientais. A análise qualitativa dos dados de cada empresa e dos dados globais das empresas por setor da indústria possibilitou ter um retrato de cada setor, procedendo-se em seguida a uma análise qualitativa global da amostra levantada. Para efeito de análise quantitativa, foram verificados os percentuais relativos às variáveis-chave e feitas análises correlacionais entre os setores da indústria e as variáveis, com a utilização de gráficos e tabelas para quantificação, demonstração e conclusões da pesquisa. Os dados permitem ainda uma análise quantitativa das variáveis numéricas e escalares, mediante estudos sobre a importância de cada um deles para os setores específicos.

\section{Resultados}

A análise dos dados foi predominantemente qualitativa, com o auxílio do software Sphinx, para aplicar o método estatístico descritivo na elaboração de tabelas e gráficos, a partir das variáveis básicas.

\section{Participação e perfil das empresas pesquisadas}

O universo pesquisado é composto de 55 empresas de seis segmentos industriais, conforme classificação da Federação das Industrias do Ceará. O índice de respostas atingiu a significativa marca de $66 \%$.

Tabela 1 - Percentual de respostas coletadas por setor

\begin{tabular}{lcc}
\hline SETOR & $\begin{array}{c}\text { NÚMERO DE } \\
\text { CITAÇÕES }\end{array}$ & FREQÜÊNCIA\% \\
\hline Beneficiamento de castanha de caju & 6 & $17,1 \%$ \\
\hline Outros freios e suas partes (metal-mecânico) & 7 & $20,0 \%$ \\
\hline Coureiro-calçadista & 5 & $14,3 \%$ \\
\hline Gorduras, óleos e ceras & 3 & $8,6 \%$ \\
\hline Lagosta e camarão & 9 & $25,7 \%$ \\
\hline Fruticultura & 1 & $2,9 \%$ \\
\hline Têxtil & 4 & $11,4 \%$ \\
\hline TOTAL & 35 & $100,0 \%$ \\
\hline
\end{tabular}

Fonte: pesquisa direta.

O número de empresas respondentes oscila, conforme o setor, já que o total compreendido pelos critérios de seleção da pesquisa apresenta uma variação, conforme mostra a tabela 2.

Tabela 2 - Amostra total por setor versus respostas por setor

\begin{tabular}{lccc}
\hline SETOR & AMOSTRA & RESPOSTAS & PARTICIPAÇÃO \\
\hline Beneficiamento de castanha de caju & 6 & 6 & $100,0 \%$ \\
\hline Outros freios e suas partes (metal-mecânico) & 8 & 7 & $87,5 \%$ \\
\hline Coureiro-calçadista & 15 & 5 & $33,3 \%$ \\
\hline Gorduras, óleos e ceras & 4 & 3 & $75,0 \%$ \\
\hline Lagosta e camarão & 14 & 9 & $64,3 \%$ \\
\hline Fruticultura & 2 & 1 & $50,0 \%$ \\
\hline Têxtil & 6 & 4 & $66,6 \%$ \\
\hline TOTAL & 55 & 35 & - \\
\hline
\end{tabular}

Fonte: pesquisa direta. 
O setor de beneficiamento de castanha de caju - que reúne grandes indústrias exportadoras para diversos países - participou maciçamente da pesquisa, e nele o índice de respostas foi de $100 \%$. O setor denominado "outros freios e suas partes" reúne fabricantes de vários tipos de produtos, como tambor de freios para automóveis, fogões, geladeiras, tampas para garrafas e material elétrico. O setor de óleos, gorduras e ceras esteve representado apenas por indústrias que beneficiam cera de carnaúba, pois as outras atividades do setor não se enquadram nos critérios da pesquisa. $\mathrm{O}$ setor coureiro-calçadista ocupa lugar de destaque na exportação de couro, principalmente o chamado couro azulado, valorizado pela facilidade de adequações e mudanças, inclusive, na sua cor. Esse couro geralmente é de origem bovina; mas o setor começa a explorar o couro de origem caprina, que permite também o aproveitamento da lã. Vale ressaltar, que desse segmento também fazem parte os fabricantes dos chamados produtos finais, como sapatos, cintos e bolsas, dentre outros. Quanto ao setor têxtil, dele fazem parte grandes empresas; algumas delas exportadoras de fio, além de outras fabricantes e exportadoras dos mais diversos tipos de tecidos. Os setores de lagosta e camarão desenvolvem a pesca e a carcinicultura; no caso, a cultura do camarão, um dos setores em expansão no Ceará. Já a fruticultura é uma das prioridades para o governo do estado, e por isso também vem se expandindo. Esse setor exporta grande quantidade de melão, bananas, uva e abacaxi, além do coco, que, com uma demanda crescente, ganha mercado em vários países.

A maioria das empresas pesquisadas está consolidada em seu segmento, atuando há mais de 10 anos no mercado nacional. Para essas firmas, no entanto, a exportação é atividade mais recente.

Tabela 3 - Tempo de atuação das empresas no mercado.

\begin{tabular}{lcc}
\hline TEMPO DE ATUAÇÃO & No DE EMPRESAS & FREQÜÊECIA \% \\
\hline Até 5 anos & 3 & $8,6 \%$ \\
\hline Mais de 5 anos & 8 & $22,8 \%$ \\
\hline Mais de 10 anos & 9 & $25,7 \%$ \\
\hline Mais de 20 anos & 5 & $14,3 \%$ \\
\hline Mais de 30 anos & 9 & $25,7 \%$ \\
\hline Mais de 40 anos & 1 & $2,9 \%$ \\
\hline TOTAL & 35 & $100,0 \%$ \\
\hline
\end{tabular}

Fonte: pesquisa direta.

Os mercados-alvo das empresas pesquisadas são Europa, Ásia, África, China, Índia, América do Norte, América Central e Oriente Médio; Europa e os EUA, citados com mais frequiência. A maior ou menor participação de cada atividade nos diferentes mercados é determinada pelo tipo de produto oferecido.

A princípio, seriam aplicados os questionários aos gestores da área investigada na pesquisa, o que não foi possível já que muitas empresas não têm responsável específico pela área ambiental. Dessa forma, os entrevistados ocupavam os mais variados cargos nas empresas, majoritariamente em nível estratégico. Em muitos casos, as ações ambientais pesquisadas estão ligadas às atividades de qualidade e segurança no trabalho. $\mathrm{Na}$ área de qualidade, podem existir cargos voltados para o trabalho com o meio ambiente, mas isso não é regra. O controle e o acompanhamento na área ambiental é feito, em grande parte, por consultorias. Um alto percentual de respostas aponta a existência de uma área de meio ambiente nas empresas, mas verificou-se in loco que ela não existe como área específica, e que suas atribuições são exercidas por outras áreas.

Confirmando a hipótese de que a legislação é um dos principais condicionantes para o desenvolvimento ambiental das empresas, um percentual considerável de citações aponta o setor jurídico das organizações como responsável pelo acompanhamento das exigências ambientais legais.

\section{Consciência ambiental}

No questionário, foram colocadas algumas alternativas que indicassem o que representam as questões ambientais para os empresários, avaliando seu grau de conscientização. A tabela 4 apresenta os resultados. 


\begin{tabular}{lcc}
\multicolumn{4}{c}{ Tabela 4 - Importância do meio ambiente para os empresários } \\
\hline MOTIVO & No DE CITAÇÕES & FREQÜËNCIA\% \\
\hline Obrigações legais & 26 & $74,3 \%$ \\
\hline Exigência dos clientes & 7 & $20,0 \%$ \\
\hline Permanência no mercado & 16 & $45,7 \%$ \\
\hline Conquista de novos mercados & 18 & $51,4 \%$ \\
\hline Responsabilidade social da empresa & 22 & $62,9 \%$ \\
\hline Contribuição pela preservação meio ambiente & 27 & $77,1 \%$ \\
\hline TOTAL & 35 & $100,0 \%$ \\
\hline
\end{tabular}

Fonte: pesquisa direta.

As opções mais citadas são as que consideram a contribuição do empresário pela preservação do meio ambiente e o cuidado com as questões ambientais como "obrigações legais" a serem cumpridas pela empresa, com percentuais de respostas de $77,1 \%$ e $74,3 \%$, respectivamente. Em seguida, são citadas por ordem, a "responsabilidade social" empresarial, a "conquista de novos mercados", a "permanência no mercado" e as "exigências de clientes". Os resultados mostram a legislação e a sociedade civil organizada - onde estão inseridos o mercado e os clientes - como fatores preponderantes para o investimento dos empresários em ações de preservação ambiental. Entretanto, os resultados também apontam percentuais significativos, relacionados à preocupação com essas questões e a responsabilidade social empresarial.

De fato, houve um avanço, mas insuficiente para representar uma mudança real de comportamento. Os resultados não condizem com as ações desenvolvidas pelos empresários. Conforme mostra o gráfico 1, a questão ambiental continua sendo um assunto restrito ao nível estratégico das empresas onde foi aplicado grande parte dos questionários. Isso favorece um discurso que causa boa impressão sobre a empresa, ainda que também possa ocorrer em níveis inferiores, já que todos querem passar uma boa imagem.

Gráfico 1 - Nivel hierárquico que controla a gestão ambiental (pesquisa direta)

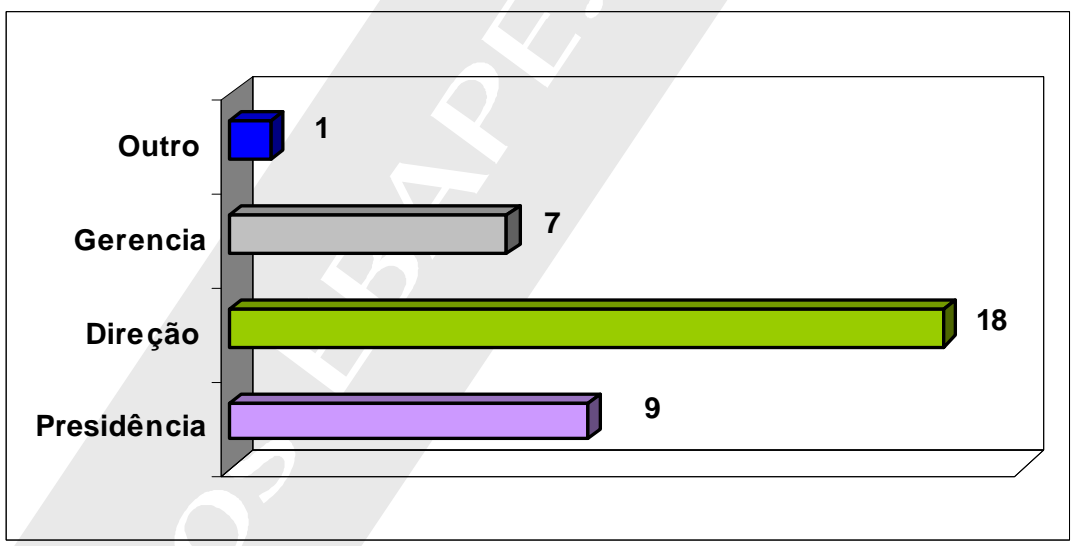

Fonte: elaborado pelos autores a partir de dados da pesquisa direta.

A preocupação com a imagem da empresa é mais um condicionante, que, no entanto pode significar apenas ações inconsistentes. A sociedade, mais consciente, cobra das empresas, pois sabe que pode sofre as consequiências da sua irresponsabilidade. Mesmo assim, é visível que a preocupação com o mercado é mais importante do que com os clientes. Quem dita o que deve ser feito é a concorrência. O intuito é sempre o de não ficar para trás e garantir espaço no mercado.

Podemos perceber pela análise por setor que o posicionamento varia em relação às respostas; o que, contudo, não interfere no entendimento do contexto. É evidente que quanto maior o percentual de exportações das empresas, mais preocupadas elas estarão em se adequar às exigências dos agentes de pressão ambiental. A 
grande preocupação com a legislação e com o mercado é uma característica dos setores com maior percentual de exportação.

\section{Ações desenvolvidas pelas empresas em prol do meio ambiente}

O gráfico 2 mostra que a maior parte das empresas afirma ter uma política ambiental formal, desenvolvendo as ações pertinentes conforme suas necessidades, embora a maioria dos seus sistemas de gestão não sejam certificáveis.

Gráfico 2 - Formalização das políticas de gestão ambiental- (pesquisa direta)

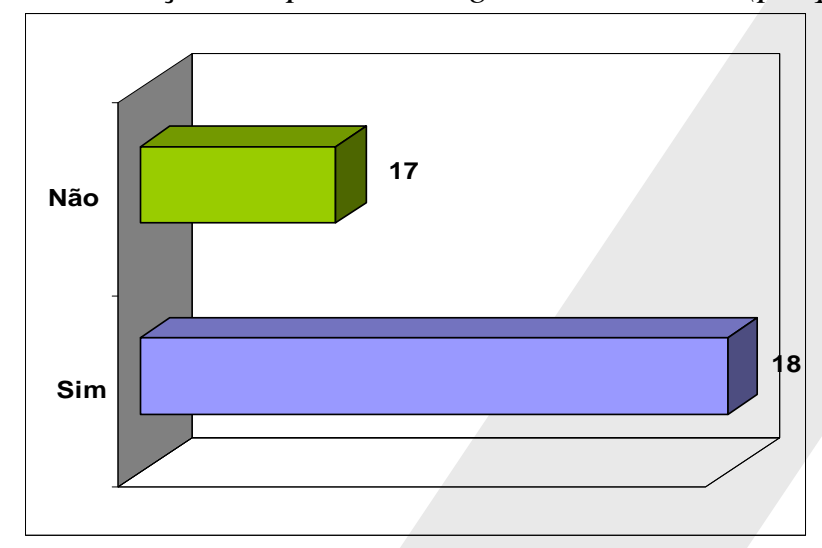

Fonte: elaborado pelos autores a partir de dados da pesquisa direta.

O gráfico 3 refere-se às ações efetivamente realizadas pelas empresas:

Gráfico 3 - Tipos de práticas adotadas pelas empresas em relação às questões ambientais (pesquisa direta)

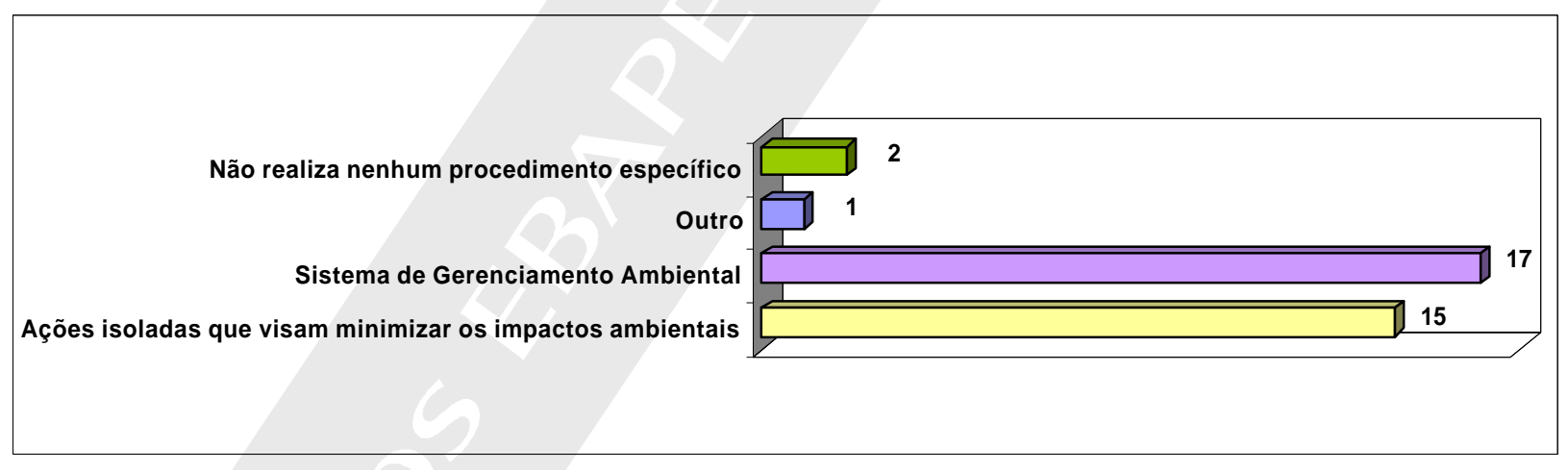

Fonte: elaborado pelos autores a partir de dados da pesquisa direta.

A maioria das empresas pesquisadas $-48,6 \%$ das respostas - tem seu próprio sistema de gestão ambiental. Na maioria dos casos, esses sistemas de gestão não estão obrigatoriamente relacionados a certificações externas, nem seguem os critérios devidos. Além disso, em qualquer atividade, os sistemas de gestão ambiental não são confiáveis, quando não se tem uma política ambiental definida e formalizada na empresa; o que foi registrado em $48 \%$ do universo pesquisado. Nesse sentido, cabe observar que a ISO 14000 não é uma prioridade para $40 \%$ das indústrias exportadoras cearenses.

A tabela 5 apresenta os resultados referentes ao tipo de certificação predominante nas empresas, que são os sistemas de gestão ambiental próprios. 
Tabela 5 - Situação das empresas em relação a sistemas de gestão ambiental (SGA)

\begin{tabular}{lcc}
\hline IMPLEMENTAÇÃO DE SGA & No DE CITAÇÕES & FREQÜ̂̂̂NCIA\% \\
\hline Sim, certificado pela NBR ISO 14001. & 3 & $8,6 \%$ \\
\hline Sim, em processo de certificação pela NBR ISO 14001 & 2 & $5,7 \%$ \\
\hline Sim, mas não certificável & 16 & $45,7 \%$ \\
\hline Não está nos planos da empresa & 14 & $40,0 \%$ \\
\hline TOTAL & 35 & $100,0 \%$ \\
\hline
\end{tabular}

Fonte: pesquisa direta.

Em alguns casos, os empresários procuram certificações junto a órgãos diretamente relacionados à sua atividade, para assim atender algumas das exigências que condicionam a exportação de seus produtos. São igualmente significativas as citações que consideram o desenvolvimento de ações específicas para controle de impacto ambiental conforme as necessidades e especificidades da empresa. $\mathrm{O}$ número de empresas que não adotam procedimento algum ou que adotam outros tipos de procedimentos é pequeno; o que é animador e ao mesmo tempo preocupante. Se de fato existe um comprometimento com o meio ambiente da parte do empresariado cearense, os problemas deveriam diminuir, não aumentar. Tal fato pode ser explicado pela predominância da chamada "maquiagem verde" ou pela adoção de práticas ineficientes.

Vale ressaltar que alguns dos setores pesquisados estão mais suscetíveis à necessidade de certificações do tipo ISO, o que está diretamente relacionado com as pressões de ordem mercadológica. Um fato curioso é que outros setores exportam praticamente sem nenhuma exigência quanto aos aspectos ambientais. Na realidade, cada país faz diferentes exigências, até em relação ao tipo de produto importado. Assim acontece com o setor de lagosta e camarão e o de beneficiamento de castanha de caju, talvez, por causa de uma maior preocupação por serem gêneros alimentícios que se não forem corretamente manuseados causam, direta ou indiretamente, sérios riscos à saúde. Quanto ao setor têxtil, este também é afetado por um nível maior de exigências; que podem ser normas dos clientes ou uma certificação verde para os seus produtos. De qualquer forma, não fogem da regra geral de condicionamento em função do mercado.

Outro fator importante a ser considerado é a relação entre fornecedores e clientes. Algumas das empresas pesquisadas atendem aos mesmos clientes há mais de 25 anos, daí porque não há restrições para as relações comerciais. Isso pode ser suficiente para que as exigências sejam abrandadas, já que se estabelece uma relação de fidelidade e credibilidade. A tabela 6 confirma essa assertiva. 
Tabela 6 - Exigências dos clientes por setor

\begin{tabular}{lcccccccc}
\hline EXIGENCIAS & \multicolumn{1}{c}{ SETORES } \\
\cline { 2 - 9 } & Castanha & Metal-mecânico & $\begin{array}{c}\text { Coureiro- } \\
\text { calçadista }\end{array}$ & $\begin{array}{c}\text { Gorduras e } \\
\text { óleos } \\
\text { vegetais }\end{array}$ & $\begin{array}{c}\text { Lagosta e } \\
\text { camarão }\end{array}$ & Fruticultura & Têxtil TOTAL \\
\hline Selo verde & 0 & 0 & 0 & 0 & 0 & 0 & 0 & 0 \\
\hline ISO 14001 & 0 & 1 & 0 & 0 & 0 & 0 & 1 \\
\hline $\begin{array}{l}\text { Normas } \\
\text { internas }\end{array}$ & 4 & 1 & 2 & 1 & 5 & 1 & 0 & 14 \\
\hline Outros & 0 & 0 & 0 & 0 & 1 & 0 & 0 & 1 \\
\hline $\begin{array}{l}\text { Não fazem } \\
\text { exigências }\end{array}$ & 2 & 5 & 3 & 2 & 3 & 0 & 3 & 18 \\
\hline TOTAL & 6 & 7 & 5 & 3 & 9 & 1 & 4 & 35 \\
\hline
\end{tabular}

Fonte: pesquisa direta.

Assim, enquanto a legislação do país de destino ou o próprio cliente não exigir - ou, então, não surgir um concorrente com preço competitivo que ofereça esse diferencial, representando a risco de perda no market share da empresa -, não serão feitos maiores investimentos relacionados aos aspectos ambientais. Entre os empresários ainda predomina uma postura reativa em relação ao meio ambiente, o que contribui para o agravamento dos problemas ambientais. Mesmo assim, a maioria das empresas pesquisadas coloca como constante o investimento em redução e controle do impacto ambiental de suas atividades.

Tabela 7 - Percepção do investimento em ações mbientais

\begin{tabular}{lc}
\hline PERCEPÇÃO & FREQÜÊNCIA \% \\
\hline Investimento & $57,0 \%$ \\
\hline Oportunidade de novos negócios & $22,7 \%$ \\
\hline Custo & $20,3 \%$ \\
\hline TOTAL & $100,0 \%$ \\
\hline \multicolumn{2}{c}{ Fonte: pesquisa direta. }
\end{tabular}

Quando questionados sobre como percebem o investimento em gestão ambiental (tabela 7), a maioria acredita que representa um investimento ou a possibilidade de novos negócios. É lamentável que a noção que os empresários têm sobre esse tipo de investimento ainda seja restrita ou equivocada, quando confrontada com o tipo de ações que vêm sendo desenvolvidas. Ainda não há consciência do que o investimento em gestão ambiental realmente representa para a empresa. Não há um entendimento claro de que gestão ambiental é a aplicação eficiente de todos os recursos envolvidos numa atividade, qualquer que seja, e do retorno financeiro que esse tipo de investimento pode trazer a médio e longo prazos. Muitos são os benefícios trazidos por esse tipo de investimento; mas, como já foi dito, o cerne da questão é outro.

\section{Condicionantes para a gestão ambiental nas empresas pesquisadas}

Os fatores que condicionam o investimento em gestão ambiental envolvem os aspectos legais e a sociedade civil organizada, na qual se inserem a sociedade, os clientes e o mercado, em geral.

Vale aqui definir quem está sendo representado em cada uma dessas classes. Quando se fala em sociedade, está sendo feita referência aos consumidores verdes e às ONGs. Os clientes são todos aqueles que adquirem produtos ou serviços fornecidos pelas empresas. $\mathrm{O}$ mercado é composto pelas agências de fomento, pelos bancos, seguradoras e pelas empresas concorrentes. O gráfico 4 mostra os percentuais de participação desse agentes. 


\section{Gráfico 4 - Fatores externos que influenciam as decisões estratégicas das empresas por setor pesquisado (pesquisa direta)}

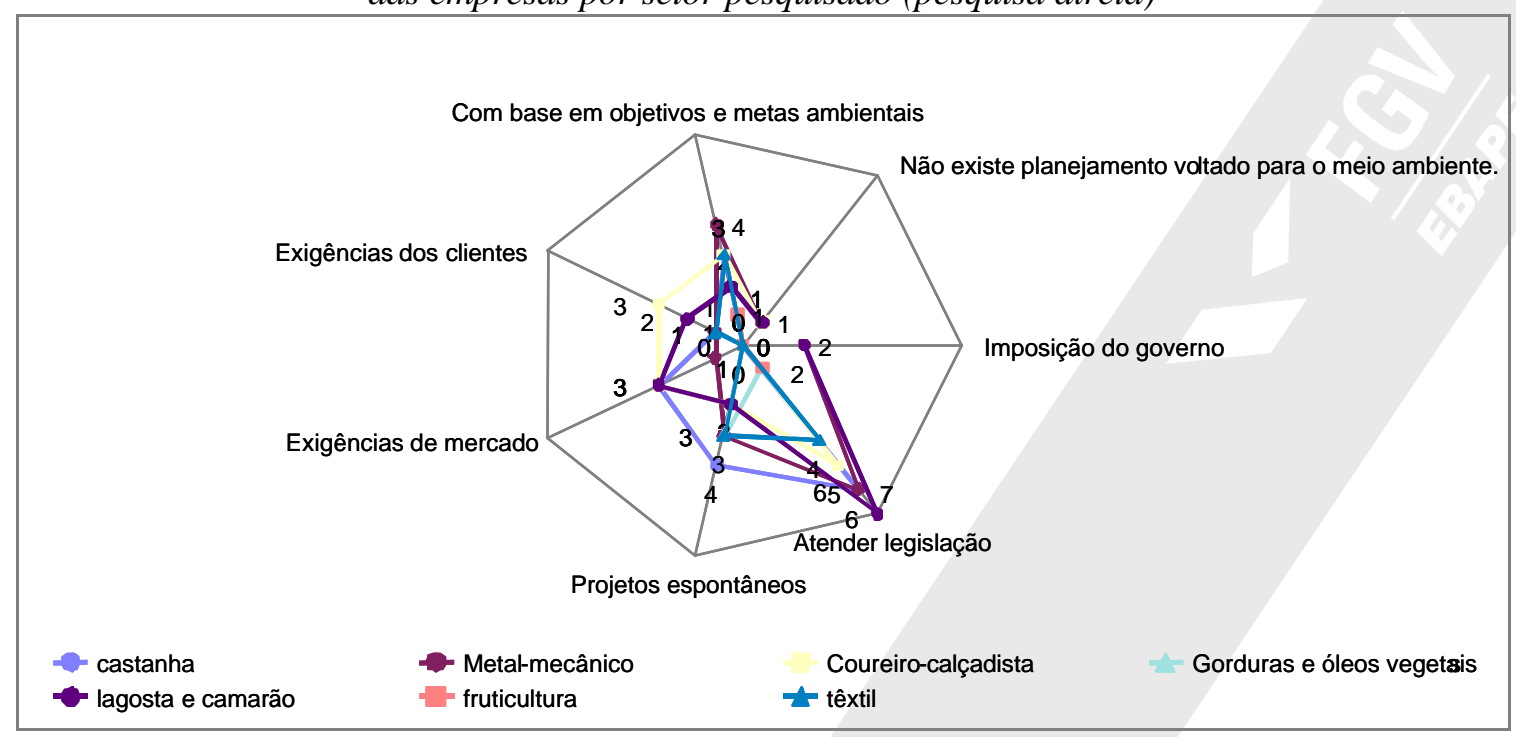

Fonte: elaborado pelos autores a partir de dados da pesquisa direta.

Apesar de observada uma variação entre os setores, verifica-se que em relação aos aspectos legais a preocupação é bem equilibrada. Aparecem de forma significativa os clientes e o mercado, o que confirma os pressupostos da pesquisa. Em função do número de sistemas de gestão ambiental desenvolvidos pelas empresas com base em suas necessidades e realidade, as citações relativas a objetivos e metas ambientais e a projetos espontâneos aparecem em número significativo. Contudo, a maioria das ações desenvolvidas pelas empresas pesquisadas, em qualquer âmbito, é realmente motivada por fatores externos. A legislação e o mercado ditam as regras. As empresas dispõem de oportunidades sem precedentes para desfrutar de novos mercados, mas esses estão cada vez mais competitivos. Os sistemas de gestão ambiental são implantados em função da oportunidade de atendê-los. Uma empresa com um sistema de gestão ambiental se diferencia em relação à concorrência. No entanto, considerando que há um encarecimento do seu produto, se os concorrentes não fazem o mesmo, o meio ambiente e a sua preservação são deixados em segundo plano.

Até o momento, não predominam as ações conscientes e espontâneas. Não que isso seja regra, mas a conscientização ainda é incipiente para reverter um quadro em que os problemas se agravam. A maioria das empresas pesquisadas tem um único propósito, o lucro, e portanto todo o seu esforço é em função desse objetivo. Mesmo as organizações que hoje realizam grandes investimentos em ações de responsabilidade socioambiental têm interesses relacionados ao seu desempenho no mercado e à conquista e fidelização de um número cada vez maior de clientes. As ações pela preservação dos recursos naturais, reciclagem e reutilização de materiais e destinação final de resíduos tendem a criar uma imagem positiva dessas empresas. O diferencial competitivo estaria então na imagem da empresa. 
Gráfico 5 - Ações que seriam realizadas pelas empresas independentemente de pressões externas (pesquisa direta)

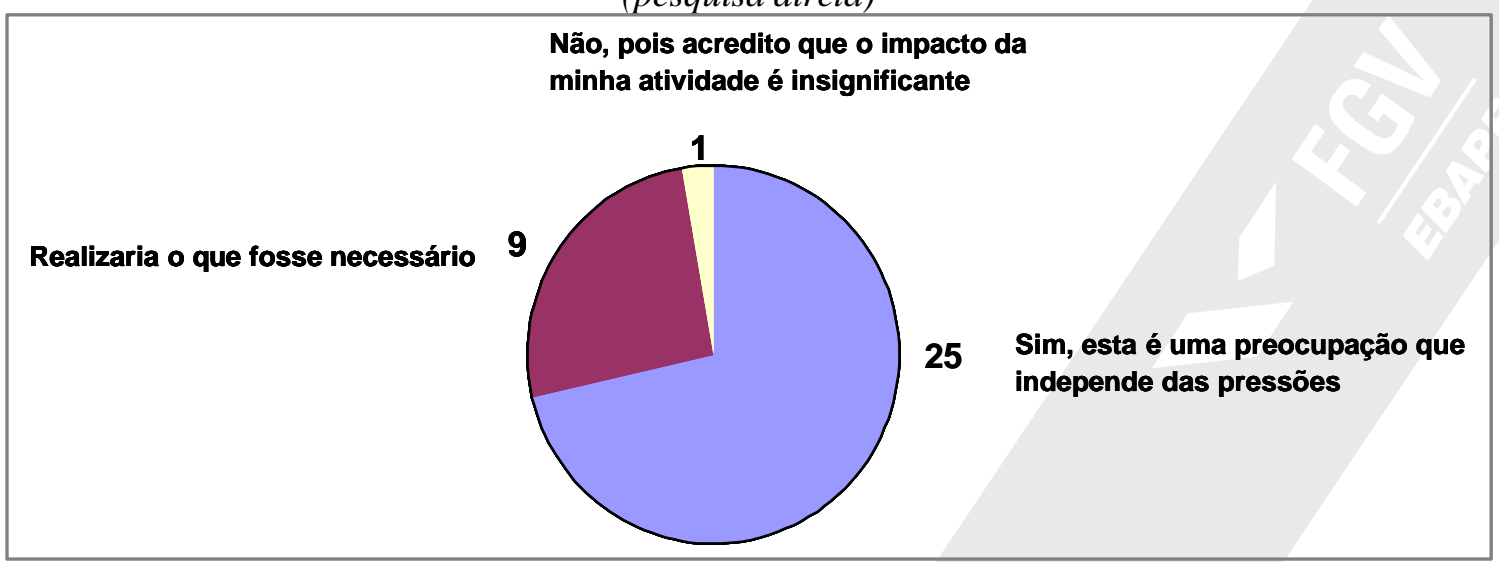

Fonte: elaborado pelos autores a partir de dados da pesquisa direta.

O gráfico 5 mostra que apesar de predominarem as respostas positivas $-71,4 \%$ na opção considerada como socialmente mais responsável -, as citações que demonstram um certo descaso com as atividades ambientais ainda são altas. De qualquer forma, o desenvolvimento de ações preventivas e corretivas vai se tornando cada vez mais freqüente. $\mathrm{O}$ ideal seria que tais ações fossem motivadas pela consciência e pelo projeto de desenvolvimento de uma atividade sustentável.

Ainda que esse despertar seja lento, o mundo empresarial está em evolução. Se os condicionantes externos contribuem para um melhor tratamento dessas questões, que sejam cada vez mais fortes. Nesse sentido, cabe destacar que os movimentos ambientalistas foram os que mais contribuíram para a mudança de postura da sociedade em relação ao meio ambiente.

Este artigo procurou retratar a situação do setor industrial, mas cabe ressaltar que outros setores, como o de serviços, também são responsáveis pelos problemas ambientais. Deve ser observado, que não se coloca aqui um impasse entre desenvolvimento e preservação ambiental, pois existem muitas maneiras de conciliar as duas coisas. No entanto, é necessária uma postura diferenciada por parte dos empresários; uma atitude que priorize cada vez mais o meio ambiente. Uma postura que não seja pautada apenas pela preocupação com a concorrência e o mercado, nem com o pagamento de multas; mas que esteja voltada para o desenvolvimento de uma cultura de preservação e de sustentabilidade.

\section{Conclusão}

As mudanças na economia mundial forçaram as indústrias a se adequarem a uma nova realidade. Não apenas por parte dos consumidores, mas da sociedade, em geral -, surgiu uma preocupação com o meio ambiente que gerou uma pressão crescente sobre indústria, no sentido de que esta se responsabilize pelo impacto ambiental que suas atividades possam causar. Por sua vez, o governo intervém através de políticas ambientais que induzem à mudanças nas práticas das empresas.

Este estudo atingiu seus objetivos quando conseguiu mostrar claramente a forte relação entre as pressões externas e as respostas das empresas; ou seja, identificou que, quanto ao meio ambiente, a postura empresarial é predominantemente reativa. Tais pressões têm sido necessárias para que as empresas mudem sua concepção sobre a questão ambiental.

Em relação às práticas ambientais no ambiente empresarial, é inegável que houve uma evolução, ainda que em pequenas proporções. As empresas começaram a realizar ações voltadas à preservação do meio ambiente por 
estarem expostas a uma situação que explícita ou implicitamente significa maior grau de exigência no trato da questão ambiental.

É fato que a evolução é um processo, e como todo processo, acontece de forma gradual. Não se deve desmerecer o que já foi alcançado. Este estudo, contudo, foi direcionado a empresas que devem ser consideradas exemplos de atuação, o que causa preocupação. Se empresas desse porte ainda não podem ser consideradas exemplos de conduta ambiental, a situação das de menor porte - não sujeitas a exigências do mercado externo e a legislações específicas para exportação- é bem pior. Na realidade, como se pode perceber, a questão ambiental está inserida num contexto maior, e enquanto essa realidade não mudar, não será possível dar a essa questão o tratamento que merece. 


\section{Referências bibliográficas}

ALM EIDA, J. et al. Planejamento ambiental: caminho para participação popular e gestão ambiental para o nosso futuro comum - uma necessidade, um desafio. Rio de Janeiro: Thex, 1999.

BARBIERI, J.C. Gestão Ambiental Empresarial. São Paulo: Saraiva, 2004.

CAIRNCORSS, F. Making polluters pay. In: COSTING the Earth. Cambridge: Harvard Business School Press, 1992.

CSILLAG, J. M.; CSILLAG, P. A evolução da preocupação ambiental nas empresas. In: ENCONTRO NACIONAL SOBRE GESTÃO EMPRESARIAL E MEIO AM BIENTE (ENGEMA), 6., 2001, São Paulo. Anais... São Paulo: Engema, 2001. 1 CD-ROM.

LAYARGUES, P. P. o discurso empresarial verde e ideologia da racionalidade econômica. São Paulo: Annablume, 1998.

MIRANDA, N. G.; SAMUDIO, E. M.; DOURADO, F. M. A estratégia de operações e a variável ambiental. Revista de Administração, São Paulo, v.32, n.1, jan./mar. 1997.

NIZARD, L.; TOURNON, J. Social perception and social demands in environmental matters. In: OECD - Environmental damage costs. Paris: Organization for Economic Cooperation and Development (OECD), 1974. p.305-330.

NOELI, L. Desafio da gestão ambiental. Banas Ambiental, São Paulo, ano I, n.5, p.12, abril 2001.

TACHIZAWA, T. Gestão ambiental e responsabilidade social corporativa. São Paulo: Atlas, 2002.

VALLE, C. E. Qualidade ambiental: como ser competitivo protegendo o meio ambiente (como se preparar para as normas ISO 14000). São Paulo: Pioneira, 1995 